\title{
Three Years of Population-Based Cancer Registration in Kumasi: Providing Evidence for Population-Based Cancer Surveillance in Ghana
}

\author{
Dennis O. Laryea ${ }^{\star 1,2}$, Fred K. Awittor ${ }^{2}$, Cobbold Sonia² and Kwame O. Boadu ${ }^{3}$ \\ ${ }^{1}$ Public Health Unit, Komfo Anokye Teaching Hospital, Kumasi, Ghana; ${ }^{2}$ Kumasi Cancer Registry, Kumasi, Ghana; ${ }^{3}$ Kumasi South \\ Regional Hospital, Kumasi, Ghana
}

\section{Objective}

To describe the operations and review data from the Kumasi Cancer Registry for the period 2012 to 2014

\section{Introduction}

Cancer Registration is the systematic collection of data on cancers and the use of such information for action. Population-based cancer registration is not common practice in developing countries. Ghana has had no population-based cancer registry till 2012 when the Kumasi Cancer Registry was established. Established initially as a hospital-based cancer registry, the $\mathrm{KsCR}$ has made significant strides in the collection and analysis of data on cancers in Kumasi. We describe the operations of the registry and provide information on data analysis from information collected by the registry for the three year period 2012 to 2014 .

\section{Methods}

Data from the Kumasi Cancer Registry for the years 2012, 2013 and 2014 was reviewed. The reference population for the registry is the city of Kumasi as designated by the 2010 Ghana Population and Housing Census. The registry collects data on cancers seen at the clinical departments of the Kumasi South Regional, Manhyia District, Tafo Government, Suntreso Government and the Komfo Anokye Teaching Hospitals. The Pathology and Haematology laboratories of KATH were also sources of data as was the Kumasi Birth and Deaths Registry. Demographic, clinical and laboratory data was abstracted from the folders of all identified cases of cancers. Cancer sites were coded using the International Classification of Diseases for Oncology (ICD-O) 3rd Edition and entered into processed electronically using Canreg 5 software. Data was analysis involved the use of Canreg 5 and Epi Info Version 7.1.4.

\section{Results}

A total of 1,078 cases of cancer were recorded among residents of Kumasi over the three year period. The majority of cases were among females $(64.2 \%)$. The mean age at incidence in males was 50.4 years and that for females 51.2 years. Breast (35.1\%), Cervix (23.7\%), Ovary (7.9\%), Liver (3.8\%) and Endometrium (3.2\%) were the top five $\mathrm{c}$

cancers were

$(3.4 \%)$ and Bone marrow (2.9\%). Out of the total cases recorded, 54 $(5 \%)$ were in children 14 years and below. Bone marrow $(18.52 \%)$, Kidney (14.8\%), Abdomen (9.3\%), Head, face or neck (9.3\%) and Retina $(7.4 \%)$ were the common cancers in children. The majority of the diagnoses were based on the histology of primary site $(58.7 \%)$, clinical diagnosis (19.2\%) death certificates (11.5\%), Clinical investigation $(8.3 \%)$ and cytology or haematology $(1.7 \%)$.

\section{Conclusions}

Population-based cancer surveillance targeting a properly defined geographic area provides better opportunity for good quality data on cancers in Ghana. This three year data from Kumasi provides evidence to support this. There is the need to establish more such registries to improve data quality for planning cancer prevention and control programmes in Ghana.

\section{Keywords}

Cancer registration; surveillance; Ghana

\section{Acknowledgments}

All staff of he Public Health Unit and the Oncology Department of the Komfo Anokye Teaching Hospital. We wish to also acknowledge the support of Health Information officers of the Kumasi South, Manhyia, Suntreso, Tafo and MCH Hospitals in Kumasi

\section{References}

O'Brien KS, Soliman AS, Awuah B, Jiggae E, Osei-Bonsu E, Quayson $\mathrm{S}$, et al. Establishing effective registration systems in resourcelimited settings: cancer registration in kumasi,ghana. J Regist Manag. 2013;40(2):70-7.

Jensen O, Parkin DM, Maclennan R, Muir C, Skeet R, editors. Cancer Registration: Principles and Methods [Internet]. Lyon, France: International Agency for Research on Cancer; 1991 [cited $2015 \mathrm{Jul}$ 28]. Available from: http://www.iarc.fr/en/publications/pdfs-online/ epi/sp95/SP95.pdf

Laryea DO, Awuah B, Amoako YA, Osei-Bonsu E, Dogbe J, LarsenReindorf R, et al. Cancer incidence in Ghana, 2012: evidence from a population-based cancer registry. BMC Cancer. 2014 May 23;14(1):362.

Fritz A, Percy C, Jack A, Shanmugaratnam K, Sobin L, Parkin DM, et al., editors. International Classification of Diseases for Oncology. Geneva, Switzerland: World Health Organisation; 2000.

\section{*Dennis O. Laryea}

E-mail: denola@live.com 